\title{
Phylogenetic Positions of Desulfofustis glycolicus gen. nov., sp. nov., and Syntrophobotulus glycolicus gen. nov., sp. nov., Two New Strict Anaerobes Growing with Glycolic Acid
}

\author{
MICHAEL FRIEDRICH ${ }^{1} \uparrow$ NINA SPRINGER, ${ }^{2}$ WOLFGANG LUDWIG, ${ }^{2}$ AND BERNHARD SCHINK ${ }^{1}$ * \\ Fakultät für Biologie, Universität Konstanz, D-78434 Konstanz, ${ }^{1}$ and Lehrstuhl für Mikrobiologie der Technischen \\ Universität München, D-80290 Munich, ${ }^{2}$ Germany
}

\begin{abstract}
The glycolate-oxidizing, sulfate-reducing bacterium strain PerGlyS and the syntrophically glycolate-oxidizing bacterium strain FIGlyR were studied with respect to their phylogenetic relationships on the basis of in vitro amplification and direct sequencing of $16 \mathrm{~S}$ rRNA-encoding DNA. Strain PerGlyS clustered with representatives of the $\delta$ subclass of the class Proteobacteria, close to "Desulforhopalus vacuolatus" but sufficiently distinct to preclude its assignment to this genus. These organisms, together with Desulfobulbus propionicus, represent a phylogenetic subgroup among members of the $\delta$ subclass of Proteobacteria. Strain FIGlyR was found to cluster with the gram-positive bacteria with low-G $+\mathrm{C}$ DNA, and Desulfitobacterium dehalogenans and Desulfotomaculum orientis are its closest relatives. Other species of the genus Desulfotomaculum are phylogenetically only moderately closely related to these organisms. These results necessitate the establishment of new genera and species for these two strains. Strain PerGlyS was designated the type strain of Desulfofustis glycolicus gen. nov., sp. nov., and strain FlGlyR was designated the type strain of Syntrophobotulus glycolicus gen. nov., sp. nov.
\end{abstract}

Glycolate is an important constituent of fruits and sugar cane $(15,23)$ and is excreted by algae and autotrophic prokaryotes under conditions of carbon dioxide limitation and excess oxygen (1-3). Aerobic degradation of glycolate has been studied in detail; its anaerobic degradation has aroused interest only recently $(9,12)$. Defined cocultures of fermenting bacteria with homoacetogenic or methanogenic bacteria were isolated which converted glycolate completely to carbon dioxide and hydrogen, with concomitant reduction of carbon dioxide to either acetate or methane (9). The primary fermenting partner in these cocultures was isolated later in pure culture with glyoxylate as the substrate (strain FlGlyR; 11). This strain has been studied in detail with respect to its biochemistry; glycolate oxidation to glyoxylate and vice versa is coupled to a membrane-bound electron transport system that catalyzes either a proton potential-driven reversed electron transport from glycolate to hydrogen or a hydrogen-dependent glyoxylate reduction coupled to ATP synthesis by electron transport phosphorylation $(10,11)$. Also a glycolate-oxidizing sulfate-reducing bacterium, strain PerGlyS, was isolated that deserves attention because of its rather high desulforubidin content and the fact that only some part of acetyl intermediates is oxidized to $\mathrm{CO}_{2}(12)$.

The present communication reports on the phylogenetic positions of these two strains and is based on sequence data obtained by direct sequencing of 16S rRNA-encoding DNA.

\section{MATERIALS AND METHODS}

Pure cultures of strains FlGlyR (DSM 8271) and PerGlyS (DSM 9705) were taken from our laboratory collection. Both have been deposited with the Deutsche Sammlung von Mikroorganismen und Zellkulturen GmbH, Braunschweig, Germany, under the reference numbers indicated. Strain FlGlyR was originally isolated from anoxic sewage sludge, and strain PerGlyS was from marine sediment obtained from a channel in Venice, Italy.

* Corresponding author. Mailing address: Fakultät für Biologie, Universität Konstanz, Postfach 5560, D-78434 Konstanz, Germany.

$\dagger$ Present address: Department of Microbiology, Montana State University, Bozeman, MT 59717.
Both strains were cultivated in a bicarbonate-buffered, sulfide- or cysteinereduced mineral medium $(21,30)$ which contained trace element solution SL10 (29), selenite-tungstate solution (29), and seven-vitamin solution (30). Details of cultivation and characterization are given in the original descriptions $(9,12)$.

In vitro amplification and direct sequencing of $16 \mathrm{~S}$ rRNA encoding DNA were performed as described earlier (24). The new sequences were added to an alignment of about 5,000 complete or partial 16S rRNA primary structures from bacteria $(17,27)$ by using the alignment tool of the ARB program package (25). Phylogenetic analyses were performed by applying the distance matrix (ARB, PHYLIP; 8), maximum-parsimony (ARB, PHYLIP), and maximum-likelihood (fastDNAml; 17) methods to different sets of data. Distance matrix and maximum-parsimony analyses were performed with sets of data comprising all available $16 \mathrm{~S}$ rRNA primary structures from gram-positive bacteria with low-G+C DNA (about 850 sequences) and the $\delta$ subclass of the class Proteobacteria (66 sequences), as well as selected reference sequences from each of the remaining major phylogenetic groups of bacteria. Maximum-likelihood methods were used to analyze subsets of about 50 sequences comprising the homologous sequences of the nearest neighbors of the organisms studied here and selected outgroup references from other phylogenetic groups. The sets of data varied with respect to the reference sequences, as well as the alignment positions included. The variabilities of the individual alignment positions were determined by using the respective tool of the ARB package and used as a criterion to successively remove highly variable positions from the set of data. This was done to recognize and minimize treeing artifacts resulting from alignment errors, database inconsistencies, and false identities (multiple base changes) in highly variable regions.

Nucleotide sequence accession numbers. The $16 \mathrm{~S}$ rRNA-encoding DNA sequences of strains PerGlyS and FlGlyR were entered into the Ribosomal Database under accession numbers 99707 and 99706 , respectively.

\section{RESULTS AND DISCUSSION}

The 16S rRNA gene sequences from glycolate-utilizing strains PerGlyS and FlGlyR were determined by direct sequencing of in vitro-amplified rRNA-encoding DNA. The moderate overall similarity $(78 \%)$ of the two sequences indicates that the strains represent different lines of descent. The isolates PerGlyS and FlGlyR could unambiguously be assigned to the major bacterial phylogenetic groups comprising the $\delta$ subclass of Proteobacteria and the gram-positive bacteria with low-G+C DNA, respectively (18).

The phylogenetic relationships of strains PerGlyS and FlGlyR and a selection of related bacteria are shown in Fig. 1. The tree is based on the results obtained by performing a distance matrix analysis of a set of data comprising all currently 


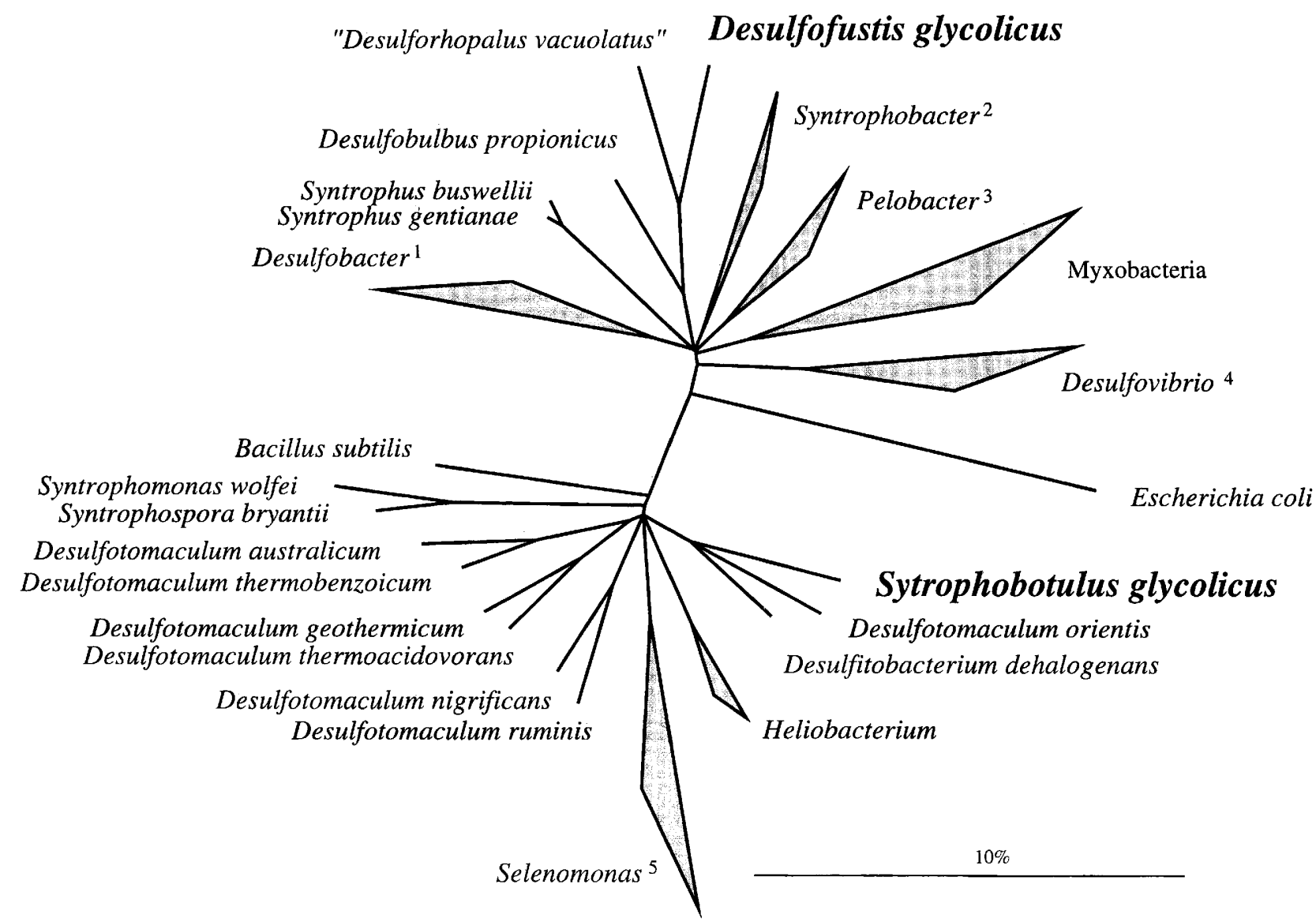

FIG. 1. 16S rRNA-based phylogenetic tree reflecting the relationships of glycolate-utilizing strains PerGlyS (Desulfofustis glycolicus) and FIGlyR (Syntrophobotulus glycolicus). The tree topology was derived by performing distance matrix analyses and corrected in accordance with the results of maximum-parsimony and maximum-likelihood analyses. The subtrees of Proteobacteria and gram-positive bacteria were optimized independently by including sequence positions which contain identical residues in at least $50 \%$ of all available $16 \mathrm{~S}$ rRNA sequences from the $\delta$ subclass of Proteobacteria and gram-positive bacteria with DNA with low G+C content, respectively. The triangles indicate groups of phylogenetically related species or genera. The bar indicates $10 \%$ estimated sequence divergence. 1 , Desulfobacter spp. plus Desulfobacterium, Desulfobacula, Desulfobotulus, Desulfococcus, and Desulfosarcina spp.; 2, Syntrophobacter spp. plus Desulforhabdus and Desulfoarculum spp.; 3 , Pelobacter spp. plus Desulfuromonas and Geobacter spp.; 4, Desulfovibrio spp. plus Bilophila and Desulfomicrobium spp.; 5, Selenomonas spp. plus Acidaminococcus, Acetonema, Dialister, Megasphaera, Pectinatus, Phascolarctobacterium, Selenomonas, Veillonella, and Zymophilus spp.

available $16 \mathrm{~S}$ rRNA sequences from the (phylogenetically) gram-positive bacteria with low-G $+\mathrm{C}$ DNA and the $\delta$ subclass of Proteobacteria. Homologous primary structures from selected representatives of all major phylogenetic groups $(17,32)$ were included as references. Only sequence positions which contain identical residues in at least $50 \%$ of all available sequences from gram-positive bacteria with low-G+C DNA were used for tree construction. This was done to reduce potential treeing artifacts which may result from multiple base changes at highly variable positions (16). Given that no closely related organisms are known or have been analyzed with respect to their $16 \mathrm{~S}$ rRNAs, deletion of highly variable sequence positions should not reduce the phylogenetic information content of the sets of data (16). Changing the selection of positions by applying the $50 \%$ invariance criterion to the set of data of available $\delta$-subclass proteobacterial sequences did not change the respective subtree. The tree topology was evaluated by performing maximum-parsimony analyses of the same sets of data, as well as maximum-likelihood analyses of reduced sets of data (about 50 sequences) comprising the selection shown in Fig. 1 and a varying collection of additional reference sequences. The subtrees of Proteobacteria and gram-positive bacteria were optimized independently, including sequence posi- tions which contain identical residues in at least $50 \%$ of all available $16 \mathrm{~S}$ rRNA sequences from the $\delta$ subclass of Proteobacteria and gram-positive bacteria with low-G+C DNA, respectively.

Multifurcations in the tree of Fig. 1 indicate branchings for which a relative order could not unambiguously be determined or was not supported by (at least the majority of) the analyses performed by applying different treeing methods. Escherichia coli and Bacillus subtilis were included in Fig. 1 to indicate the phylogenetic depths of Proteobacteria and gram-positive bacteria with low-G+C DNA, respectively.

Among the Proteobacteria of the $\delta$ subclass, strain PerGlys, "Desulforhopalus" sp. (14), and Desulfobulbus sp. (6) represent a phylogenetic cluster as also indicated by similarity values of 90.6 and $86.5 \%$, respectively (Table 1 ). The corresponding values shared by strain PerGlyS and the other representatives of the $\delta$ subclass are 80.6 and $85.4 \%$. No closer relationship between this cluster and Syntrophobacter (13), Syntrophus (28), or Desulfobulbus spp. was supported by results obtained by applying different treeing analyses.

Within the phylogenetic group of gram-positive bacteria with low-G+C DNA, Desulfitobacterium dehalogenans (26) and Desulfotomaculum orientis (6) share $91.2 \%$ and $88.6 \% 16 \mathrm{~S}$ 
TABLE 1. Overall 16S rRNA sequence similarities for strain PerGlyS and related reference organisms ${ }^{a}$

\begin{tabular}{|c|c|c|c|c|c|c|c|c|c|c|c|}
\hline \multirow{2}{*}{ Organism(s) } & \multicolumn{11}{|c|}{$\%$ Similarity to: } \\
\hline & PGS & Dva & Dpr & Sbu & Sge & Dba & Sba & $\mathrm{Pba}$ & $\mathrm{Mba}$ & Des & Eco \\
\hline \multicolumn{12}{|l|}{ PGS } \\
\hline Dva & 90.6 & & & & & & & & & & \\
\hline Dpr & 86.5 & 87.6 & & & & & & & & & \\
\hline Sbu & 84.7 & 84.1 & 86.0 & & & & & & & & \\
\hline Sge & 85.4 & 85.0 & 86.3 & 98.3 & & & & & & & \\
\hline Dba & 82.2 & 83.5 & 83.6 & 84.9 & 85.2 & & & & & & \\
\hline Sba & 83.8 & 83.4 & 84.2 & 83.8 & 84.0 & 82.6 & & & & & \\
\hline $\mathrm{Pba}$ & 83.4 & 84.5 & 84.3 & 85.0 & 85.4 & 83.9 & 84.5 & & & & \\
\hline Mba & 80.6 & 81.0 & 82.3 & 82.7 & 82.8 & 80.4 & 82.1 & 83.0 & & & \\
\hline Des & 81.8 & 81.9 & 82.1 & 81.3 & 81.7 & 81.4 & 81.3 & 82.4 & 80.0 & & \\
\hline Eco & 79.7 & 79.8 & 79.8 & 80.3 & 80.1 & 78.8 & 78.8 & 81.0 & 79.0 & 78.9 & \\
\hline Gpl & 78.3 & 78.9 & 79.3 & 79.5 & 79.7 & 78.6 & 79.6 & 80.7 & 78.3 & 79.2 & 77.4 \\
\hline
\end{tabular}

${ }^{a}$ The values indicate the fraction of identical residues within the respective sequence pairs calculated by including only positions present in both sequences. Mean values are given for phylogenetic groups. Abbreviations: Dba, Desulfobacter, Desulfobacterium, Desulfobacula, Desulfobotulus, Desulfococcus, and Desulfosarcina spp.; Des, Desulfovibrio spp.; Dpr, Desulfobulbus propionicus; Dva, Desulforhopalus vacuolatus; Eco, Escherichia coli; Mba, myxobacteria; Pba, Pelobacter, Desulfuromonas, Desulfuromusa, and Geobacter spp.; Gpl, gram-positive bacteria with DNA with low G+C content; PGS, PerGlyS; Sba, Syntrophobacter, Desulforhabdus, and Desulfoarculum spp.; Sbu, Syntrophus buswellii; Sge, Syntrophus gentianae.

rRNA sequence similarity, respectively, with strain FlGlyR (Table 2). The corresponding values for these organisms and other members of the major phylogenetic group of gram-positive bacteria with DNA with a low $\mathrm{G}+\mathrm{C}$ content are slightly lower (83.8 to $85.9 \%$ ). Most analyses supported a moderate relationship of this group to Heliobacterium spp. (33), the remaining Desulfotomaculum species $(6,7,19,20)$; and other phylogenetic gram positives with gram-negative cell walls such as Acidaminococcus, Acetonema, Dialister, Megasphaera, Pectinatus, Phascolarctobacterium, Selenomonas, Veillonella, and Zymophilus spp. (4, 5, 22, 31, 34). However, the significance of such a grouping is low, as indicated by the short internode distance of the branch containing the former organisms or groups and the Syntrophospora-Syntrophomonas (34) branch.

The results presented here justify the establishment of new genera and species for strains PerGlyS and FlGlyR, for which we propose the names Desulfofustis glycolicus and Syntrophobotulus glycolicus, respectively. The descriptions are based on references 9 and 12 .
Description of Desulfofustis gen. nov. Desulfofustis (De.sul .fo.fus'tis. L. prefix de, off, L. n. sulfur, sulfur, fustis, club). M. L. m. n. Desulfofustis, a sulfate-reducing club. The description of this new genus is identical to that of its only species, $D$. glycolicus sp. nov.

Description of Desulfofustis glycolicus sp. nov. glycolicus (gly.co'li.cus. M. L. n. acidum glycolicum, glycolic acid). glycolicus, referring to glycolic acid as the key substrate of this species. Gram-negative, rod-shaped bacteria, straight to slightly curved, 2.0 to 4.5 by $0.55 \mu \mathrm{m}$ in size, occurring typically as single cells. Motile by one subterminally inserted flagellum, no spore formation.

Strictly anaerobic bacteria, growing chemotrophically by oxidation of glycolate, glyoxylate, L-lactate, L-malate, fumarate, succinate, yeast extract, or hydrogen (in the presence of carbon dioxide and traces of acetate), with sulfate as an electron acceptor. Other substrates (formate, acetate, propionate, butyrate, isobutyrate, isovalerate, valerate, caproate, 3-methylbutyrate, fructose, glucose, oxalate, pimelate, glutarate, glycolal-

TABLE 2. Overall 16S rRNA sequence similarities for strains FlGlyR and related reference organisms ${ }^{a}$

\begin{tabular}{|c|c|c|c|c|c|c|c|c|c|c|c|c|c|}
\hline \multirow{2}{*}{ Organism(s) } & \multicolumn{13}{|c|}{$\%$ Similarity to: } \\
\hline & FGR & $\overline{D d h}$ & Dor & Hel & Sel & Dni & Dru & Dau & Dge & Dth & Sbr & Swf & Bsu \\
\hline FGR & & & & & & & & & & & & & \\
\hline $\mathrm{Ddh}$ & 91.2 & & & & & & & & & & & & \\
\hline Dor & 88.6 & 92.1 & & & & & & & & & & & \\
\hline Hel & 86.5 & 87.5 & 84.8 & & & & & & & & & & \\
\hline Sel & 82.6 & 83.0 & 82.2 & 82.9 & & & & & & & & & \\
\hline Dni & 84.7 & 85.5 & 83.1 & 86.3 & 82.2 & & & & & & & & \\
\hline Dru & 84.8 & 85.9 & 84.5 & 85.2 & 82.6 & 91.5 & & & & & & & \\
\hline Dau & 83.3 & 84.5 & 83.6 & 83.2 & 80.8 & 85.5 & 83.7 & & & & & & \\
\hline Dge & 83.3 & 86.3 & 84.1 & 84.4 & 82.2 & 87.1 & 86.8 & 87.3 & & & & & \\
\hline Dth & 83.6 & 85.3 & 84.2 & 84.4 & 81.9 & 86.7 & 84.6 & 90.1 & 88.5 & & & & \\
\hline Sbr & 84.6 & 84.7 & 83.5 & 84.6 & 80.8 & 83.1 & 83.4 & 84.0 & 83.0 & 84.5 & & & \\
\hline Swf & 83.6 & 84.0 & 83.5 & 83.5 & 80.2 & 82.2 & 82.6 & 84.6 & 82.6 & 84.0 & 92.8 & & \\
\hline Bsu & 83.7 & 84.3 & 83.7 & 83.9 & 81.5 & 83.4 & 83.6 & 83.1 & 83.5 & 84.5 & 82.9 & 82.6 & \\
\hline $\mathrm{Pbd}$ & 78.6 & 79.4 & 78.4 & 79.9 & 77.3 & 78.8 & 78.9 & 78.6 & 79.5 & 79.3 & 79.6 & 79.1 & 79.2 \\
\hline
\end{tabular}

${ }^{a}$ The values indicate the fraction of identical residues within the respective sequence pairs calculated by including only positions present in both sequences. Mean values are given for phylogenetic groups. Abbreviations: Bsu, Bacillus subtilis; Dau, Desulfotomaculum australicum; Ddh, Desulfitobacterium dehalogenans; Dge, Desulfotomaculum geothermicum; Dor, Desulfotomaculum orientis; Dni, Desulfotomaculum nigrificans; Dru, Desulfotomaculum ruminis; Dth, Desulfotomaculum thermobenzoicum; FGR, FlGlyR; Hel, Heliobacterium chlorum, H. fasciatum, H. gestii, H. mobilis, and H. modestocaldum; Pbd, $\delta$ subclass of Proteobacteria; Sbr, Syntrophospora bryantii; Sel, Selenomonas, Acidaminococcus, Acetonema, Dialister, Megasphaera, Pectinatus, Phascolarctobacterium, Veillonella, and Zymophilus spp.; Swf, Syntrophomonas wolfei. 
dehyde, glyceraldehyde, simple aliphatic alcohols, betaine, choline, cysteine, triethanolamine, glycine, indol, and benzoate) not oxidized. Sulfite and elemental sulfur reduced with glycolate as electron donor, thiosulfate or nitrate not reduced. Cells contain menaquinone- $5\left(\mathrm{H}_{2}\right)$, desulforubidin, and cytochromes $b$ and $c$, no desulfoviridin.

Organic substrates other than glycolate are typically incompletely oxidized, but part of acetyl intermediates may be oxidized, as well, to various extents.

$\mathrm{pH}$ range, 6.7 to 8.3 ; optimum $\mathrm{pH}, 7.3$. Temperature range, 15 to $37^{\circ} \mathrm{C}$; optimum temperature, $28^{\circ} \mathrm{C}$. Growth optimal in marine medium with $340 \mathrm{mM} \mathrm{NaCl}-14 \mathrm{mM} \mathrm{MgCl}_{2}$. Growth possible also in brackish-water medium with one-third of this salt concentration; no growth in freshwater medium. DNA base ratio, $56.2 \pm 0.1 \mathrm{~mol} \% \mathrm{G}+\mathrm{C}$ (determined by high-pressure liquid chromatography analysis). Habitat, anoxic marine sediments.

Type strain, PerGlyS (DSM 9705), deposited with the Deutsche Sammlung von Mikroorganismen und Zellkulturen.

Description of Syntrophobotulus gen. nov. Syntrophobotulus (Syn.tro.pho.bo'tu.lus. Gr. prefix syn, together, gr. v. trephein, to nourish, L. n. botulus, sausage. M. L. m. n. Syntrophobotulus, a syntrophic, sausage-like bacterium. The description of this new genus is identical to that of its only species, $S$. glycolicus sp. nov.

Description of Syntrophobotulus glycolicus sp. nov. glycolicus (gly.co'li.cus. M. L. n. acidum glycolicum, glycolic acid.) glycolicus, referring to glycolic acid, the key substrate of this species.

Rod-shaped bacterium, slightly curved, 2.5 to 3.5 by $0.5 \mu \mathrm{m}$ in size, occurring typically as single cells or in small aggregates. Nonmotile. Oval spores formed in ageing cultures at the cell ends. Gram staining is negative, ultrastructural analysis shows gram-positive cell wall architecture.

Strictly anaerobic bacteria, growing chemotrophically in pure culture by fermentative oxidation of glyoxylate. Glycolate is oxidized in syntrophic coculture with, e.g., Methanospirillum hungatei or Acetobacterium woodii as a partner. No other organic or inorganic substrates used. Glycolic acid is converted to carbon dioxide and hydrogen in syntrophic culture; glyoxylic acid is fermented in pure culture to carbon dioxide, hydrogen, and glycolic acid. Neither sulfate, sulfite, thiosulfate, elemental sulfur, nor nitrate reduced. Cells contain menaquinone-7-10, with MK-9 as major fraction. No cytochromes present. $\mathrm{pH}$ range, 6.7 to 8.3 ; optimum $\mathrm{pH}, 7.3$. Temperature range, 15 to $37^{\circ} \mathrm{C}$; optimum temperature, $28^{\circ} \mathrm{C}$. Growth optimal in freshwater medium. Growth possible also in brackish-water medium with $110 \mathrm{mM} \mathrm{NaCl}-5 \mathrm{mM} \mathrm{MgCl}$; no growth in marine medium. DNA base ratio, $46.7 \pm 0.15 \mathrm{~mol} \% \mathrm{G}+\mathrm{C}$ (determined by high-pressure liquid chromatography analysis). Habitat, sewage sludge and anoxic freshwater sediments. Type strain, FlGlyR (DSM 8271), deposited with the Deutsche Sammlung von Mikroorganismen und Zellkulturen.

\section{ACKNOWLEDGMENT}

This study was supported by a grant from the Bundesministerium für Forschung und Technologie, Bonn, Germany, in its program on biological hydrogen production.

\section{REFERENCES}

1. Bateson, M. M., and D. M. Ward. 1988. Photoexcretion and fate of glycolate in a hot spring cyanobacterial mat. Appl. Environ. Microbiol. 54:1738-1743.

2. Beck, E. 1979. Glycolate synthesis, p. 327-335. In A. Pirson and M. H. Zimmerman (ed.), Photosynthesis II. Encyclopedia of plant physiology, new series, vol. 6. Springer-Verlag KG, Berlin.

3. Codd, G. A., and B. M. Smith. 1974. Glycollate formation and excretion by the purple photosynthetic bacterium Rhodospirillum rubrum. FEBS Lett. 48:105-108.
4. Cook, G. M., F. A. Rainey, G. Chen, E. Stackebrandt, and J. B. Russell. 1994. Emendation of the description of Acidaminococcus fermentans, a trans-aconitate- and citrate-oxidizing bacterium. Int. J. Syst. Bacteriol. 44:576-578.

5. Del Dot, T., R. Osawa, and E. Stackebrandt. 1993. Phascolarctobacterium faecium, gen. nov., spec. nov., a novel taxon of the Sporomusa group of bacteria. Syst. Appl. Microbiol. 16:380-384.

6. Devereux, R., M. Delaney, F. Widdel, and D. A. Stahl. 1989. Natural relationships among sulfate-reducing eubacteria. J. Bacteriol. 171:6689-6695.

7. Farrow, J. A. E., C. Ash, S. Wallbanks, and M. D. Collins. 1991. Phylogenetic analysis of the genera Marinococcus, Planococcus and Sporosarcina and their relationships to members of the genus Bacillus. Phylogenetic analysis of Desulfotomaculum nigrificans. FEMS Microbiol. Lett. 93:167-172.

8. Felsenstein, J. 1982. Numerical methods for inferring phylogenetic trees. Q. Rev. Biol. 57:379-404.

9. Friedrich, M., U. Laderer, and B. Schink. 1991. Fermentative degradation of glycolic acid by defined syntrophic cocultures. Arch. Microbiol. 156:398-404.

10. Friedrich, M., and B. Schink. 1993. Hydrogen formation from glycolate driven by reversed electron transport in membrane vesicles of a syntrophic glycolate-oxidizing bacterium. Eur. J. Biochem. 217:233-240.

11. Friedrich, M., and B. Schink. 1995. Electron transport phosphorylation driven by glyoxylate respiration with hydrogen as electron donor in membrane vesicles of a glyoxylate-fermenting bacterium. Arch. Microbiol. 163: 268-275.

12. Friedrich, M., and B. Schink. 1995. Isolation and characterization of a desulforubidin-containing sulfate-reducing bacterium growing with glycolate. Arch. Microbiol. 164:271-279.

13. Harmsen, H. J. M., B. Wullings, A. D. L. Akkermans, W. Ludwig, and A. J. M. Stams. 1993. Phylogenetic analysis of Syntrophobacter wolinii reveals a relationship with sulfate-reducing bacteria. Arch. Microbiol. 160:238-240.

14. Isaksen, M. F., and B. B. Jørgensen. 1996. Adaption of psychrophilic and psychrotrophic sulfate-reducing bacteria to permanently cold marine environments. Appl. Environ. Microbiol. 62:408-414.

15. Karrer, W. 1958. Konstitution und Vorkommen von organischen Pflanzenstoffen. Birkhäuser, Basel.

16. Ludwig, W., and K. H. Schleifer. 1994. Bacterial phylogeny based on $16 \mathrm{~S}$ and 23S rRNA sequence analysis. FEMS Microbiol. Rev. 15:155-173.

17. Maidak, B. L., N. Larsen, M. J. McCaughey, R. Overbeek, G. Olsen, K. Fogel, J. Blandy, and C. R. Woese. 1994. The ribosomal database project. Nucleic Acids Res. 22:3485-3487.

18. Olsen, G. J., C. R. Woese, and R. Overbeek. 1994. The winds of (evolutionary) change: breathing new life into microbiology. J. Bacteriol. 176:1-6.

19. Patel, B. K., C. A. Love, and E. Stackebrandt. 1992. Helix 6 of the 16S rRNA of the bacterium Desulfotomaculum australicum exhibits an unusual structural idiosyncrasy. Nucleic Acids Res. 20:5483.

20. Redburn, A. C., and B. K. Patel. 1993. Phylogenetic analysis of Desulfotomaculum thermobenzoicum using polymerase chain reaction-amplified $16 \mathrm{~S}$ rRNA-specific DNA. FEMS Microbiol. Lett. 113:81-86.

21. Schink, B., and N. Pfennig. 1982. Fermentation of trihydroxybenzenes by Pelobacter acidigallici gen. nov. sp. nov., a new strictly anaerobic non-sporeforming bacterium. Arch. Microbiol. 133:195-201.

22. Schleifer, K. H., M. Leuteritz, N. Weiss, W. Ludwig, G. Kirchhof, and H. Seidel-Rufer. 1990. Taxonomic study of anaerobic, gram-negative, rodshaped bacteria from breweries: emended description of Pectinatus cerevisiiphilus and description of Pectinatus frisingensis sp. nov., Selenomonas lacticifex sp. nov., Zymophilus raffinosivorans gen. nov., sp. nov., and Zymophilus paucivorans sp. nov. Int. J. Syst. Bacteriol. 40:19-27.

23. Shorey, E. C. 1899 . Glycollic acid: one of the acids of sugar-cane. J. Am. Chem. Soc. 21:45-50.

24. Springer, N., W. Ludwig, R. Amann, H. J. Schmidt, H. D. Gortz, and K. H. Schleifer. 1993. Occurrence of fragmented 16S rRNA in an obligate bacterial endosymbiont of Paramecium caudatum. Proc. Natl. Acad. Sci. USA 90: 9892-9895.

25. Strunk, O., O. Gross, B. Reichel, M. May, S. Hermann, N. Stuckmann, B. Nonhoff, M. Lenke, A. Ginhart, A. Vilbig, T. Ludwig, A. Bode, K. H. Schleifer, and W. Ludwig. ARB: a software environment for sequence data. Nucleic Acids Res., in press.

26. Utkin, I., C. R. Woese, and J. Wiegel. 1994. Isolation and characterization of Desulfitobacterium dehalogenans gen. nov., sp. nov., an anaerobic bacterium which reductively dechlorinates chlorophenolic compounds. Int. J. Syst. Bacteriol. 44:612-619.

27. Van de Peer, Y., I. Van den Broeck, P. De Rijk, and R. De Wachter. 1994. Database on the structure of small ribosomal subunit RNA. Nucleic Acids Res. 22:3488-3494.

28. Wallrabenstein, C., N. Gorny, N. Springer, W. Ludwig, and B. Schink. 1995. Pure culture of Syntrophus buswellii, definition of its phylogenetic status, and description of Syntrophus gentianae sp. nov. Syst. Appl. Microbiol. 18:62-66.

29. Widdel, F., G. W. Kohring, and F. Mayer. 1983. Studies on dissimilatory sulfate-reducing bacteria that decompose fatty acids. 3. Characterisation of the filamentous gliding Desulfonema limicola gen. nov. sp. nov., and Desulfonema magnum sp. nov. Arch. Microbiol. 134:286-294.

30. Widdel, F., and N. Pfennig. 1981. Studies on dissimilatory sulfate-reducing bacteria that decompose fatty acids. I. Isolation of new sulfate-reducing 
bacteria enriched with acetate from saline environments. Description of Desulfobacter postgatei gen. nov., sp. nov. Arch. Microbiol. 129:395-400.

31. Willems, A. M. C. G., A. Willems, and M. D. Collins. 1995. Phylogenetic placement of Dialister pneumosintes (formerly Bacteroides pneumosintes) within the Sporomusa subbranch of the Clostridium subphylum of the grampositive bacteria. Int. J. Syst. Bacteriol. 45:403-405.

32. Woese, C. R. 1987. Bacterial evolution. Microbiol. Rev. 51:221-271.
33. Woese, C. R., B. A. Debrunner-Vossbrinck, H. Oyaizu, E. Stackebrandt, and W. Ludwig. 1985. Grampositive bacteria: possible photosynthetic ancestry. Science 229:762-765.

34. Zhao, H., D. Yang, C. R. Woese, and M. P. Bryant. 1990. Assignment of Clostridium bryantii to Syntrophospora bryantii gen. nov., comb. nov. on the basis of a 16S rRNA sequence analysis of its crotonate-grown pure culture. Int. J. Syst. Bacteriol. 40:40-44. 